\section{Perfect Eyes}

Lynn M.G. Gardner, HT (ASCP)

University of lowa, FC Blodi Eye Pathology Laboratory

It is extremely difficult to remove artifacts common to eye tissue such as folds, shrinking raisin effect, and parched earth effect. By adjusting our fixation and processing procedures, we attempted to reduce or eliminate these artifacts. We tested the fixatives from various vendors to determine which of them is most compatible with eye tissue and which would eliminate artifacts. We found Pen-Fix (alcoholic formalin; Richard Allen, Richland, MI) produced optimal fixation (well defined nuclear detail, without bubbling artifact). In similar testing, we found Peel-a-way (Shandon-Lipshaw, Pittsburgh, $\mathrm{PA}$ ) to be the optimal paraffin for processing and embedding ocular tissues.

Many laboratories may be called upon to process ocular (eye) tissue. With improper technique, the histologist may generate slides containing a circular piece of tissue with multiple foids and dryness (parched earth effect). Artifacts may make it difficult for pathologists to render accurate interpretations. In this article, we discuss our experience of many years in generating slides from ocular tissues that are nearly artifact-free.

\section{Procedures}

We have several guidelines for the fixation of eye tissue. Routinely, we receive enucleations (globe only) and exenterations (globe and surrounding tissue with eyelids) in $10 \%$ Neutral Buffered Formalin (NBF). As soon as it is received, we replace the $10 \%$ NBF with Pen-Fix (alcoholic formalin, Richard Allan -6101). We fix large enucleations (human, pig, cow, primate) in the Pen-Fix for 12-18 hours (without tumor) and 24-48 hours (with tumor). We fix small enucleations (mouse, rat, guinea pig) in Pen-Fix for 6-8 hours.

The fixation of orbital exenterations is at least 48 hours. Many pathologists bisect the exenteration section. In our laboratory, the pathologist frequently dissects the periocular tissue away from the eyelids and orbital contents, a procedure that allows for precise mapping of pathology. With this grossing technique, eyelid tissue or orbital tissue is marked with dyes for orientation, then cut and placed into cassettes. The eye itself may require additional fixation because the orbital fat that surrounded the globe prior to removal may have prevented adequate fixation of intraocular contents.

Processing procedures vary depending on the type and size of the tissue we are going to process. The two most important features of our processing are the fixation and the type of paraffin that is used. If fixation is performed as mentioned above, the tissue should process correctly. We found that Peel-a-way $\left(56-58^{\circ} \mathrm{C}\right)$ paraffin, which does not contain plastic polymers,

\begin{tabular}{|l|l|}
\hline \multicolumn{1}{|c|}{ STATION } & \multicolumn{1}{|c|}{ SOLUTIONS } \\
\hline $\begin{array}{l}\text { Pressure and Vacuum } \\
\text { in all stations }\end{array}$ & \\
\hline
\end{tabular}

\begin{tabular}{|ccc|}
\hline 1 & Pen Fix & $1 \mathrm{hr}$. \\
\hline 2 & Pen Fix & $1 \mathrm{hr}$. \\
\hline 3 & $80 \%$ Ethanol & $1 \mathrm{hr}$. \\
\hline 4 & $95 \%$ Ethanol & $1 \mathrm{hr}$. \\
\hline 5 & $95 \%$ Ethanol & $30 \mathrm{~min}$. \\
\hline 6 & $100 \%$ Ethanol & $1 \mathrm{hr}$. \\
\hline 7 & $100 \%$ Ethanol & $1 \mathrm{hr}$. \\
\hline 8 & Xylene & $30 \mathrm{~min}$. \\
\hline 9 & Xylene & $45 \mathrm{~min}$. \\
\hline 10 & Xylene & $1 \mathrm{hr}$. \\
\hline 11 & Paraffin & $30 \mathrm{~min}$. \\
\hline 12 & Paraffin & $30 \mathrm{~min}$. \\
\hline 13 & Paraffin & $30 \mathrm{~min}$. \\
\hline 14 & Paraffin & $30 \mathrm{~min}$. \\
\hline
\end{tabular}

- Our routine processing for human, primate, pig or other large eyes is 11-12 hours in total time. is very hard and expands well on the waterbath, thus helping to reduce tissue wrinkles and folds.

\section{Results}

Ocular tissue processed by these regiments is well-fixed and easy to cut and stain. If tissue appears to be dry, soaking the block for 10 to15 minutes in an ice bath (tray of crushed ice with $50 \mathrm{~mL}$ of distilled water) may be helpful. If the tissue is still dry, one may add approximately $100 \mathrm{~mL}$ of a $0.25 \%$ to $0.5 \%$ ammonium hydroxide solution to the ice bath and soak the tissue for another 10 to15 minutes.

\section{Discussion}

Many procedures designed for processing eye tissue, such as hand processing, are extremely time consuming, and others do not facilitate proper fixation, cutting, and staining. We have used the protocols described in this report for 6 years and have taught these techniques to others. We emphasize that using Pen-Fix for fixation and Peel-a-way paraffin for processing and embedding are key ingredients to the success of ocular histotechnique. Pen-Fix penetrates tissue rapidly, enhances routine and special staining, and is suitable for immunohistochemical and in situ hybridization techniques. Peel-a-way paraffin (for processing and embedding), a very hard paraffin, supports the eye tissue more effectively than other paraffins thus eliminating compression and wrinkling during cutting. Creating "Perfect Eyes" (Figures 1 and 2) is simplified with the use of $u$ Pen-Fix, Peel-a-way paraffin and the processing techniques presented in this paper.

\begin{tabular}{|c|c|c|c|}
\hline Station & SOLUTIONS & TIME & TIME \\
\hline $\begin{array}{l}\text { Pressure and } \\
\text { Vacuum in all } \\
\text { stations }\end{array}$ & & & \\
\hline 1 & Pen Fix & $30 \mathrm{~min}$. & skip \\
\hline 2 & Pen Fix & $15 \mathrm{~min}$. & skip \\
\hline 3 & $80 \%$ Ethanol & $15 \mathrm{~min}$. & $15 \mathrm{~min}$. \\
\hline 4 & $95 \%$ Ethanol & $15 \mathrm{~min}$. & $15 \mathrm{~min}$. \\
\hline 5 & $95 \%$ Ethanol & $30 \mathrm{~min}$. & $30 \mathrm{~min}$. \\
\hline 6 & $100 \%$ Ethanol & $15 \mathrm{~min}$. & $15 \mathrm{~min}$. \\
\hline 8 & Xylene & $15 \mathrm{~min}$. & $15 \mathrm{~min}$. \\
\hline 9 & Xylene & $15 \mathrm{~min}$. & $15 \mathrm{~min}$. \\
\hline 10 & Xylene & $30 \mathrm{~min}$. & $30 \mathrm{~min}$. \\
\hline
\end{tabular}

$\uparrow$ For smaller eyes: mouse, rat, guinea pig, our processing schedule is $4-5$ hours.

\begin{tabular}{|c|c|c|}
\hline SOLUTIONS & $\begin{array}{c}\text { TIMES IN SOLUTIONS } \\
\text { (large eyes) }\end{array}$ & $\begin{array}{c}\text { TIMES IN SOLUTIONS } \\
\text { (small eyes) }\end{array}$ \\
\hline $80 \%$ Ethanol & 2 hours & 2 hours \\
\hline $95 \%$ Ethanol & 4 hours & 2 hours \\
\hline $95 \%$ Ethanol & 4 hours & 2 hours \\
\hline $100 \%$ Ethanol & 4 hours & 2 hours \\
\hline $100 \%$ Ethanol & 4 hours & 4 hours \\
\hline $100 \%$ Ethanol & 4 hours & 3 hours \\
\hline Xylene & 4 hours & 3 hours \\
\hline Xylene & 4 hours & 2 hours \\
\hline $\begin{array}{c}\text { Paraffin (under vac- } \\
\text { uum) }\end{array}$ & 4 hours & 2 hours \\
\hline $\begin{array}{c}\text { Paraffin (under vac- } \\
\text { uum) }\end{array}$ & 4 hours & \\
\hline
\end{tabular}

$\uparrow$ The final processing schedule we use is for hand processing tissue, in case of processor malfunction. The tissue must be well fixed prior to this procedure! 


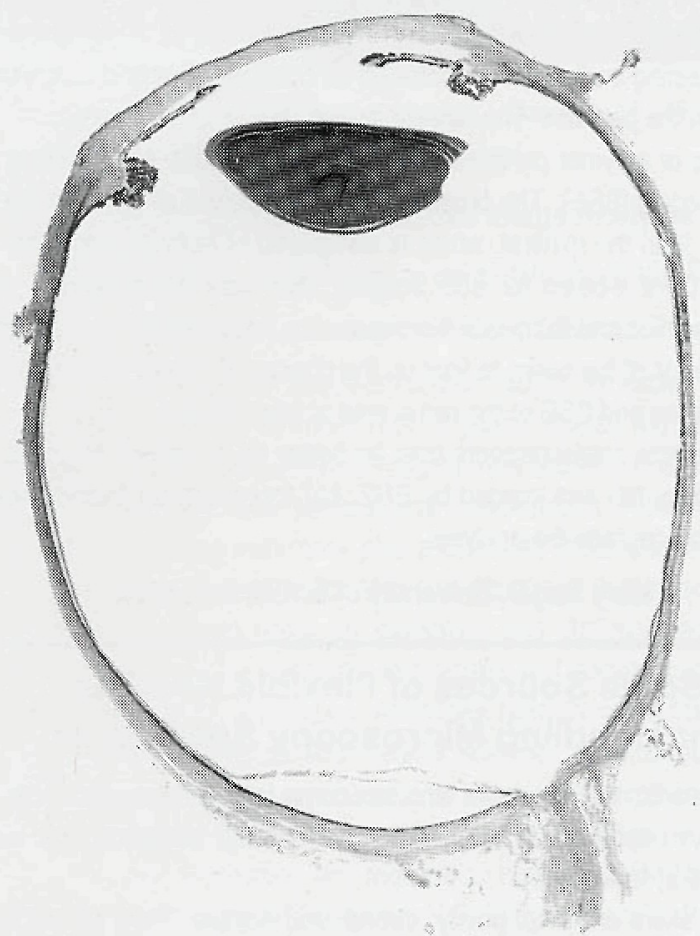

Figure 1. Postmortem eye. Note the nearly perfectly round shaape to the eye, a histologic feature that requires proper fixation, embedding, cutting and tissue expansion. Hematoxylin-eosin.

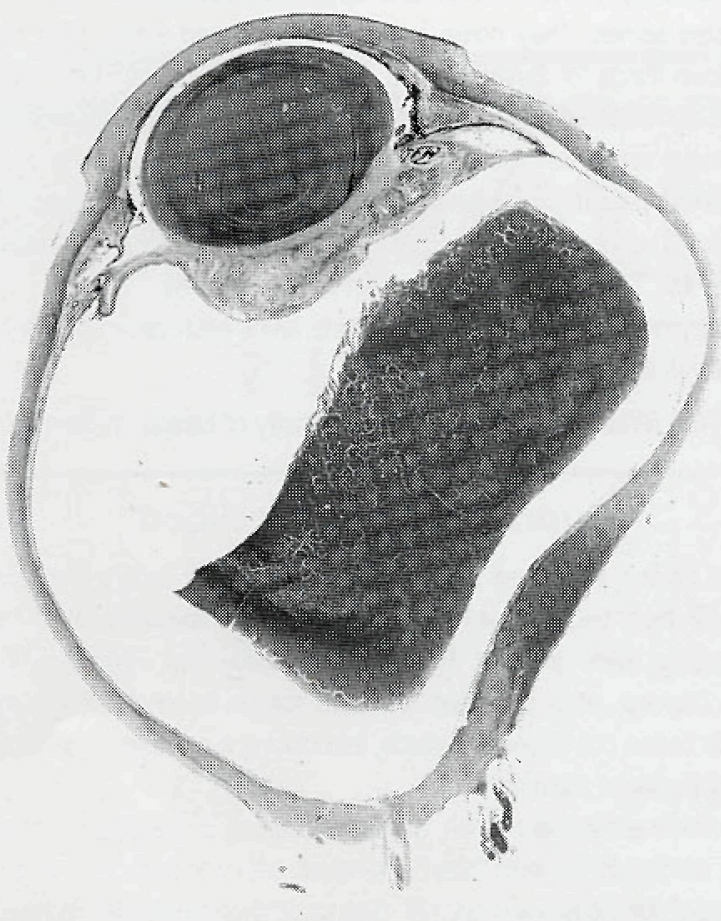

Figure 2. Surgically removed eye. The dark material in the interior of the eye is blood. Despite the presence of a large hemorrhage, the tissue sections are nearly artifact free because of the use of techniques described in this report. The eye is nogt perfectly round because of intraocular pathology. Hematoxylin-eosin.

\section{Acknowledgments}

I would like to thank Margaret Meyer who performed the graphics editing and Robert Folberg, MD, Director of the FC Blodi Eye Pathology Laboratory, who reviewed this article and offered helpful suggestions.

Disclamer: The author has no proprietary interest in any product mentioned herein

\section{The Accurate Control of the Thickness of Evaporated Carbon Films} Alwyn Eades, Lehigh University

There are two approaches to determining the thickness of a carbon film evaporated onto a specimen. One approach is to do the evaporation first and to measure the result afterwards. There are several ways to do this. The second approach is to put down a determined amount of carbon in the first place. This clearly has advantages in many cases. The method described here is of this second kind. The thickness of the carbon coating is not measured, but by a predetermined recipe, the amount put on is controlled at the time of evaporation. In principle, the thickness could be measured during the evaporation with a quartz-crystal thickness monitor. However, we find that the monitor we have does not work well with carbon.

\section{Principle}

When carbon is deposited onto gold, it forms interference colors that are well defined. They can be used to determine the thickness of the carbon.

\section{The Colors}

If carbon is evaporated onto gold, as the thickness of the carbon increases, the color changes through the following sequence: gold, orange, red, blue, grey. The change of color from red to blue is particularly sharp and clear. The change of color from red to blue occurs when the thickness of the carbon is $24.0 \mathrm{~nm}+\mathrm{j}-0.5 \mathrm{~nm}$. This result was obtained by people at Balzers using a multibeam interference technique for calibration.

\section{Details}

1) Take a glass slide (or a strip of aluminum or any other suitable substrate) and evaporate onto it a layer of gold. The thickness is not critical as long as the gold is thick enough to give an opaque film that looks like gold.

2) Mount the slide in the same chamber with the specimen to be coated with carbon. The thickness of the carbon on the slide will be $24 \mathrm{~nm}$, so arrange the distance of the slide and the sample so that (by the inverse square law) the desired thickness on the sample will occur when the thickness on the slide is $24 \mathrm{~nm}$.

3) Evaporate the carbon; stop the evaporation as the color changes from red to blue. If a normal arc is being used for the carbon evaporation, the light from the arc will allow the colors to be seen. It may be helpful to have additional good lighting anyway - try it and see. The bell jar will need to be reasonably clean.

\section{Using the Inverse Square Law.}

Let $T \mathrm{~nm}$ be the desired thickness of carbon film; let $d$ be the distance from the carbon arc to the gold slide; let $D$ be the distance from the carbon arc to the specimen. Then:

$(d / D)^{2}=T / 24$.

As a specific example, suppose that $10 \mathrm{~nm}$ of carbon is to be deposited, and the sample sits $200 \mathrm{~mm}$ from the carbon arc. Then the gold slide should be:

$d=200 \sqrt{ }(10 / 24)=129 \mathrm{~mm}$ from the arc

Reference: The information for this method was obtained from scientists at Balzers High Vacuum in the mid 1960s.

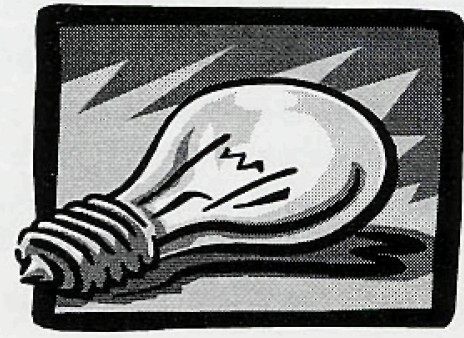

